\title{
Uptake of Palladium Using Liquid Emulsion Membrane Technique
}

\author{
Ratnesh Kumar ${ }^{1}$, Ajay Kumar Mishra ${ }^{1} \&$ K. S. Seshadri ${ }^{1}$ \\ ${ }^{1}$ Department of Atomic Energy, Kalpakkam, Tamil Nadu, India \\ Correspondence: K. S. Seshadri, Department of Atomic Energy, Kalpakkam, Tamil Nadu 603 102, India. E-mail: \\ seshubestarts@gmail.com
}

Received: April 13, 2014 Accepted: May 29, 2014 Online Published: July 3, 2014

doi:10.5539/ijc.v6n3p39

URL: http://dx.doi.org/10.5539/ijc.v6n3p39

\begin{abstract}
The waste stream generated at the reprocessing facility (first cycle raffinate-Hi level waste) contains Palladium as one of the fission products. The recovery of Palladium from the waste stream reduces the activity burden and lends its use for catalytic applications.

This paper deals with its recovery from the waste stream generated at various stages of nuclear fuel cycle using liquid emulsion membrane technique. Complexants chosen were based on the chelating ability with metal ions with high stability constant in the waste stream. Complexants 8-hydroxy quinoline, Thio salicylic acid, dithiazone, cupferron, 1-Niroso-2-naphthol, Quinalizarin were chosen as complexants. The effect of surfactant concentration, complexant concentration, agitating speed, and emulsifcation time on the emulsion stability have been studied. Treat ratio, the ratio of the emulsion phase to the external phase and the impeller speed on the removal of Palladium have been studied. Results show that stable emulsion could be prepared by using $1.5 \mathrm{ml}$ of surfactant span 80 in $50 \mathrm{ml}$ emulsion, with impeller speed $3000 \mathrm{RPM}$, for duration of 20 minutes using complexants of strength of 70-200 moles $/ \mathrm{m}^{3}$. Effective recovery of Pd could be achieved by using strippant of $\mathrm{pH}$ 1-3.7 in the emulsion phase at 250-300 RPM of impeller speed.
\end{abstract}

Keywords: emulsion, surfactant, complexants, permeation

\section{Introduction}

Conventional liquid extraction suffers from the drawbacks of being equilibrium limited and need for a separate stripping operation. Liquid emulsion technique has been recognized as promising technology as it overcomes these draw backs of the conventional liquid extraction. In general, the liquid emulsion membrane is prepared by forming an emulsion of two immiscible phases and then dispersing the emulsion into a third phase. The transport of dissolved material through the liquid membrane is termed as permeation. Since the liquid film offers much higher diffusivities and area exceeding $10,000 \mathrm{~m}^{2} / \mathrm{m}^{3}$, the fluxes of the liquid membranes are very high. Furthermore liquid membranes can be tailor made for specific applications.

LM technology can carry out extraction and stripping process simultaneously and have benefit of non equilibrium mass transfer and uphill effect where solute can be moved from low to high concentrated solution (Franken, 1997; Gu et al., 1994; Giaikwad, 2004). The main types of liquid membrane systems include Emulsion Liquid Membrane (ELM) (Li et al., 1997), Supported Liquid Membrane (SLM) (Bloch et al., 1967), Bulk Liquid Membrane (BLM), Flowing Liquid Membrane (FLM) (Teramoto et al., 1989), Supported Emulsion Liquid Membrane (SELM) (Fouad et al., 2008; Sonawane et al., 2007), Hollow Fibre Contained Liquid Membrane (HFCLM) (Gabelman et al., 1999) and Supported Liquid Membrane with Stripping Dispersion (SLMSD) (Basualto et al., 2003; Gu et al., 2006) etc. The potential advantages of LM techniques over traditional separation techniques and solid membranes techniques are lower capital and operational costs, lower energy and extractant consumption and higher concentration factors and fluxes. However LM techniques have not been adopted to large scale industrial processes yet (Zhang et al., 2000; Danesi et al., 1987; Gu et al., 2003; Lin et al., 2004; Neplenbroek et al., 1992; Bechiri et al., 2008; Zha et al., 1995) primarily due to lack of emulsification and deemulsification steps in ELM and SELM processes and membrane resistance in BLM and HFCLM processes etc. (Ren et al., 2007). 


\section{Experimental}

\subsection{Materials}

The membrane phase used is a homogeneous mixture of Xylene as organic solvent, span 80 as surfactant. AR grade extractants 8-hydroxy quinoline, Thio salicylic acid, dithiazone, cupferron, 1-Niroso-2-naphthol, Quinalizarin used were procured from Ms. E. Merck. The internal stripping phase is aq. Solution of Hydrochloric acid.

\subsection{Preparation of Emulsion}

The emulsion was prepared in a glass vessel of $100 \mathrm{~mm}$ dia. $25 \mathrm{ml}$ of the organic phase was prepared by adding surfactant span 80 in water to a $25 \mathrm{ml}$ of Xylene. $10 \mathrm{ml}$ of the internal strip phase $\mathrm{HCl}$ was added drop wise to the organic phase and the contents were simultaneously stirred by a motor fitted with a turbine impeller of $2 \mathrm{~cm}$ dia. The RPM of the impeller was measured using Digital Tachometer with totalizer/counter of make Metravi NCTM-1000. Excellent dispersion was observed and a milky white emulsion was obtained.

\subsection{Effect of Parameters and Emulsion Stability}

\subsubsection{Role of Surfactant Strength on the Emulsion Stability}

Since the surfactant plays an important role in the stability of the emulsion, the effect of surfactant strength on the emulsion stability was studied by adding $25 \mathrm{ml}$ of 0.8 to $12 \% \mathrm{~V} / \mathrm{V}(0.2 \mathrm{ml}$ to $3 \mathrm{ml}$ of surfactant span 80 in 25 $\mathrm{ml}$ of water) in $25 \mathrm{ml}$ of Xylene. The so prepared solution was stirred at 3000 RPM for 20 minutes and the emulsion so prepared was studied for the stability by finding out the time needed for the dispersion to take place. Figure 1a shows the emulsion stability time as function of strength of surfactant.

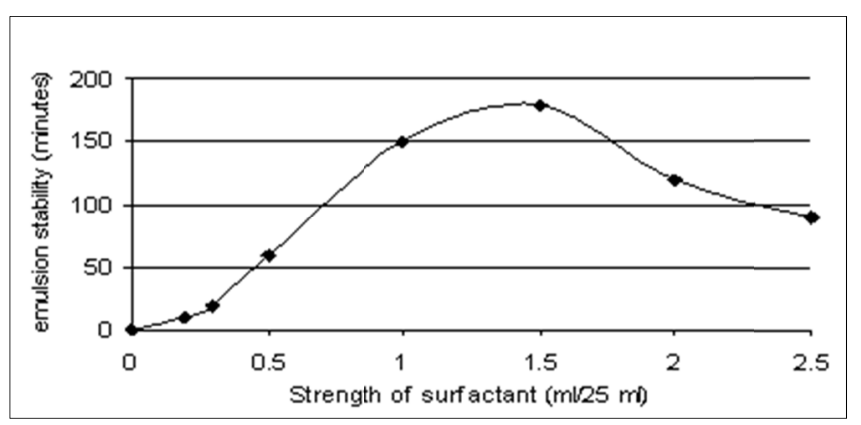

Figure 1a. Role of surfactant strength on the emulsion stability

\subsubsection{Role of Agitation Time and Agitation Speed}

Since stable emulsion needs optimum agitation speed at optimum time to withstand external variation in parameters, experiments on the study of agitation speed and agitation time was carried out by subjecting the solution for preparing the emulsion (aqueous phase containing the surfactant span 80 in water added to Xylene) to different agitation speed varying from 1000-4000 RPM for 20 minutes duration. Figure $1 \mathrm{~b}$ shows the variation of emulsion stability time as function of speed of agitator.

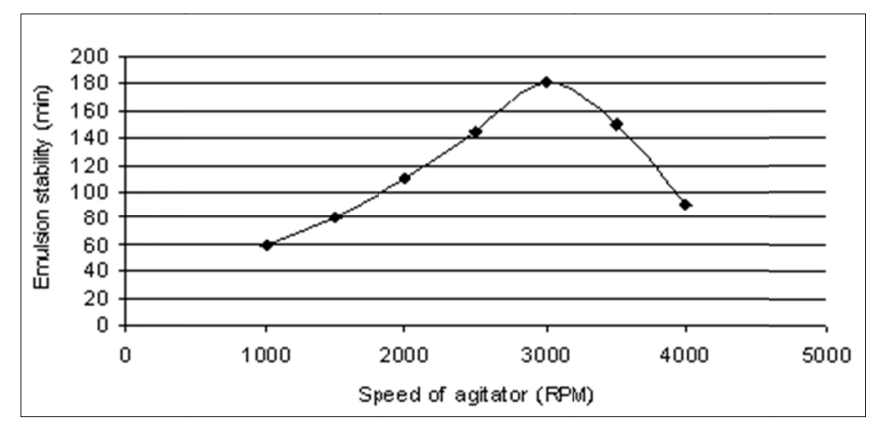

Figure 1b. Effect of agitator speed on the emulsion stability 
The experiment was repeated and the emulsion prepared at different agitation times ( 5 to 60 minutes) were studied for their emulsion stability time as function of agitation time. Figure 1c shows the emulsion stability duration as function of agitation time.

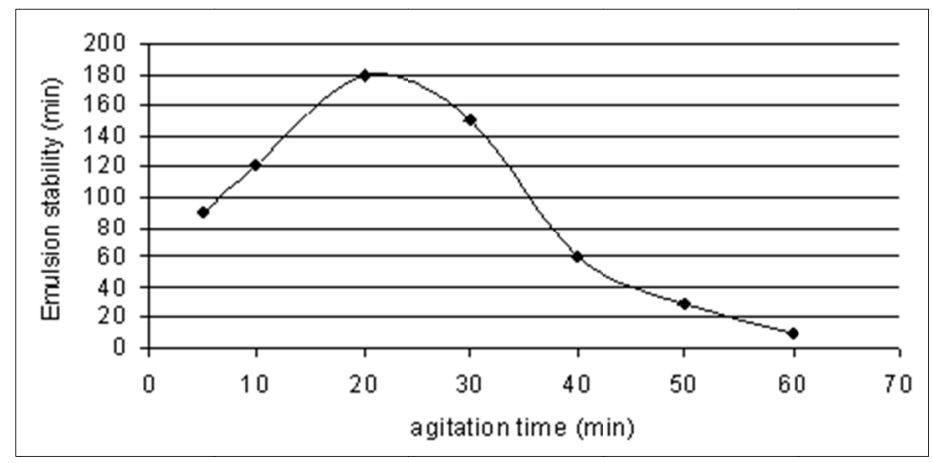

Figure 1c. Effect of agitation time on the emulsion stability

\subsubsection{Role of Complexant Strength on the Stability of Emulsion}

The complexant included in the emulsion when added to the solution containing the Palladium ion to be recovered extracts Palladium in to emulsion phase. Even though the higher strength of complexant may aid more recovery of metal ion, the limiting factor in the complexant strength is the emulsion stability due to complexant. Hence it is imperative to study the emulsion stability time as function of complexant strength included in the emulsion. The emulsion stability time was studied by preparing emulsion using $25 \mathrm{ml}$ of aqueous solution $6 \%$ $\mathrm{V} / \mathrm{V}$ of surfactant span $80 \mathrm{in} 25 \mathrm{ml}$ of Xylene with different complexants of strength 0.07 to $0.2 \mathrm{moles} / \mathrm{L}$ at 3000 RPM for 20 minutes. Figure.1d shows the emulsion stability time as function of complexant strength. In all the cases, the emulsion stability was studied from the time when the dispersion takes place as the criterion.

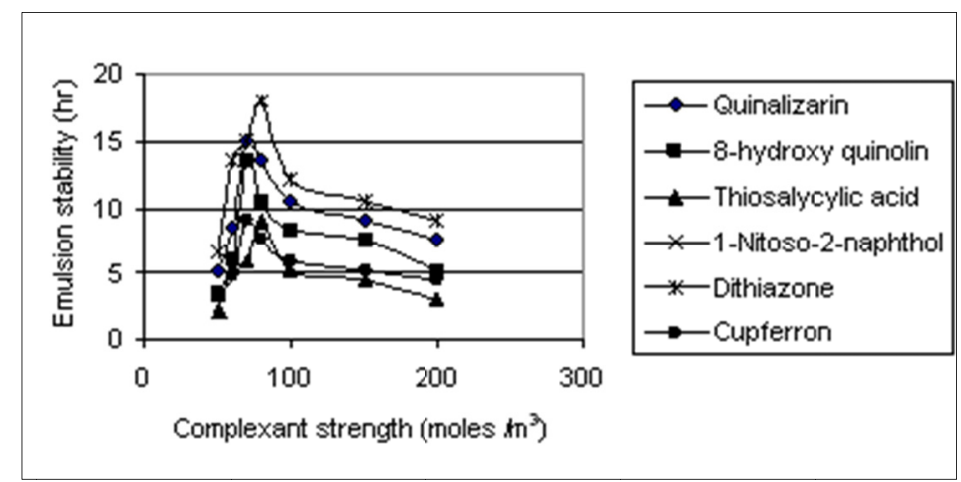

Figure 1d. Effect of complexant strength on emulsion stability

\subsection{Effect of Operating Parameters on Synthetic Effluent}

The emulsion prepared by using $25 \mathrm{ml}$ of aqueous solution of $6 \% \mathrm{~V} / \mathrm{V}$ of surfactant span 80 and $100 \mathrm{moles} / \mathrm{m}^{3}$ of the complexants viz.0.4349 g 1-nitroso-2-naphthol, $1.583 \mathrm{~g}$ dithiazone, $0.3629 \mathrm{~g}$ 8-hydroxy quinoline, $0.3049 \mathrm{~g}$ thiosalycylic aicid, $0.3875 \mathrm{~g}$ cupferron, $0.6804 \mathrm{~g}$ quinalizarin in $25 \mathrm{ml}$ of Xylene at impeller speed of $3000 \mathrm{RPM}$ for 20 minutes was used for the experiment on the uptake of Palladium from the aqueous solutions.

\subsubsection{Effect of $\mathrm{pH}$ of the Strippant Solution}

Since the $\mathrm{pH}$ of the strippant included in the emulsion is an important parameter for successful recovery of Palladium from the organic phase of emulsion to the aqueous phase of the emulsion, $50 \mathrm{ml}$ of the so prepared emulsion was added to $50 \mathrm{ml}$ of Palladium solution of strength $0.09 \mathrm{mM}$ with the strippant $\mathrm{pH}$ varying from 1.1 to 7.2. The mixed mass was stirred at 250 RPM. The emulsion phase was separated, demulsified using sodium 
chloride for the recovery of Palladium. The aqueous phase was analyzed for Palladium by AAS. Figure 2 shows the $\%$ uptake of Palladium a function of $\mathrm{pH}$ of the strippant.

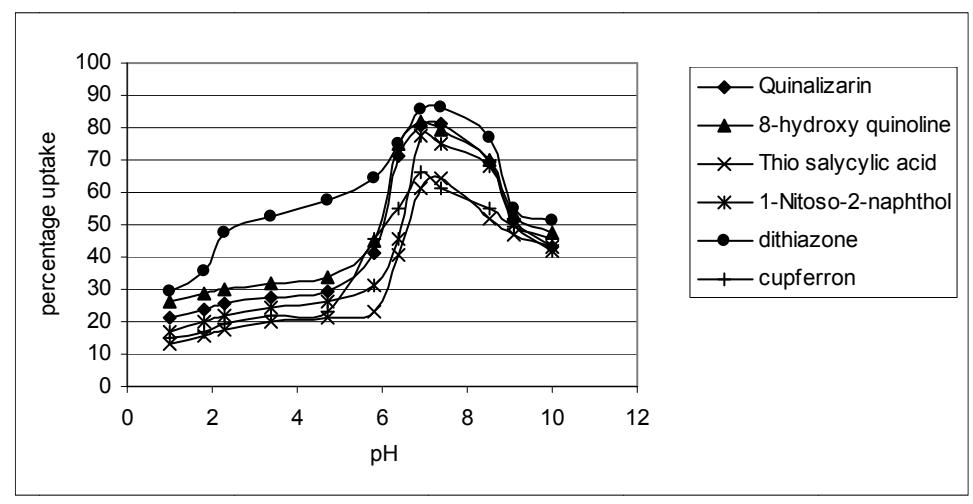

Figure 2. Uptake of Palladium as function of $\mathrm{pH}$ of strippant

\subsubsection{Kinetics of Uptake of Palladium}

To find out the kinetics of removal of Palladium, $50 \mathrm{ml}$ of emulsion prepared using different complexants with the stripping solution at the optimum $\mathrm{pH}$ was added to $50 \mathrm{ml}$ of Palladium solution of strength $0.09 \mathrm{mM}$ and the solution obtained was stirred at 250 RPM. The emulsion and aqueous phases were separated and the aqueous phase was anlaysed for Palladium at interval of 15 minutes. Figure 3 shows the \% removal of Palladium as function of time.

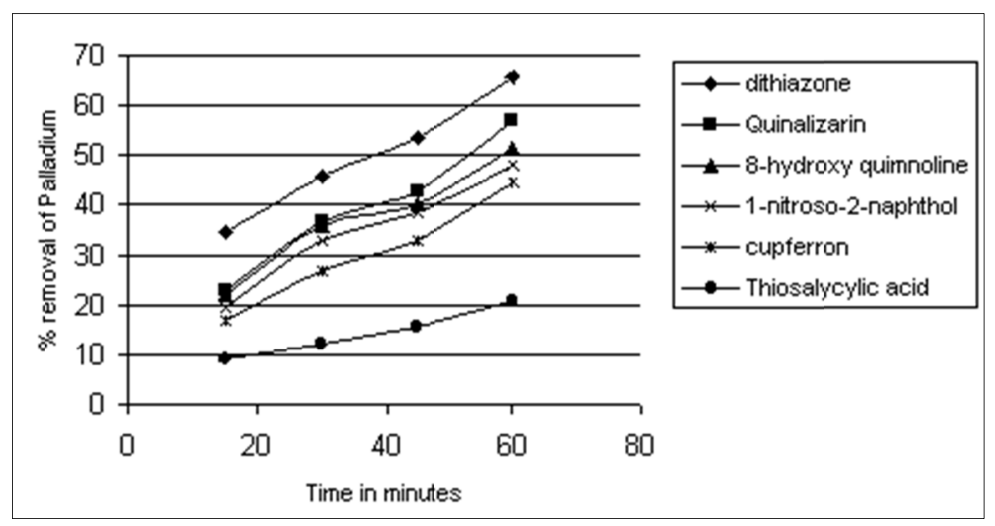

Figure 3. Kinetics of uptake of Palladium

\subsubsection{Effect of Extractants on the Uptake of Pd}

The extractant helps in thinning the membrane phase by reduction in the viscosity of the membrane phase. This will help in the transport of the solute ions for extraction. But beyond some concentration of extractant over a certain limit decreases the stability of the emulsion. Hence a compromise has to be made on the extractant strength which was done by adding $50 \mathrm{ml}$ of emulsion prepared by including different extractants at $0.07 \mathrm{~mole} / \mathrm{L}$ to $0.2 \mathrm{moles} / \mathrm{L}$. to $50 \mathrm{ml}$ solution of Palladium of strength $0.09 \mathrm{mM}$ at 1:1 Treat Ratio at the optimum $\mathrm{pH}$ of the strippant for each extractant by stirring the mix at 250 RPM for 1 hour. The emulsion and aqueous phases were separated and the strength of Palladium was analyzed in the aqueous phase. Figure 4 shows the uptake of Palladium as function of strength of different complexants. 


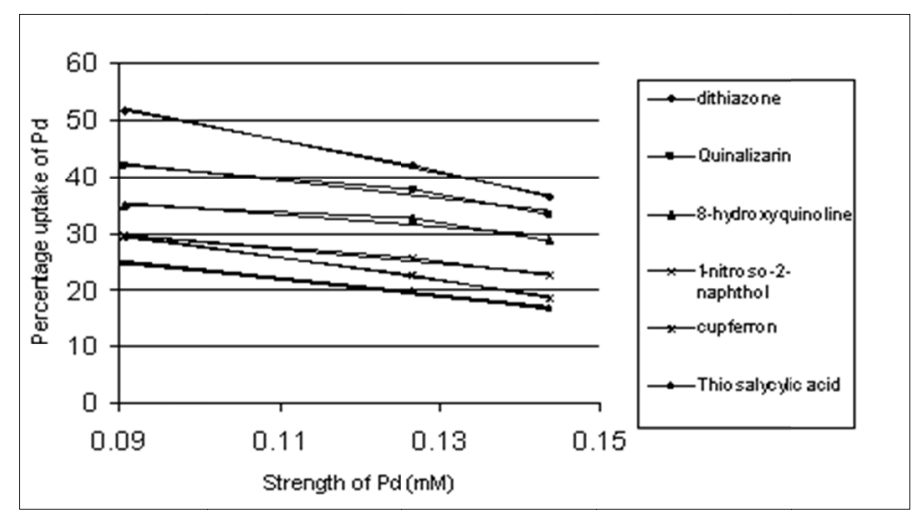

Figure 4. Uptake of Pd as function of different strength of Pd

\subsubsection{Effect of Treat Ratio}

Since the complexant present in the emulsion takes up the metal ion from the aqueous solution phase and emulsion membrane provides good surface area for permeation to take place, the volume ratio of emulsion to the aqueous phase containing the metal ion to be extracted called the treat ratio is a very important parameter. Experiments on the uptake of Palladium using emulsion membrane were carried out at optimum $\mathrm{pH}$ in the stripping solution for different complexants at different emulsion to solution volume ratio (treat ratio), 1:1, 1:2 and 1:3 keeping the aqueous solution containing the Palladium as $50 \mathrm{ml}$ and the emulsion containing various complexants at 50,100 and $150 \mathrm{ml}$ giving rise to the treat ratio as 1:1, 1:2 and 1:3. After stirring at $250 \mathrm{RPM}$, the emulsion and aqueous phases were separated, and the aqueous phase was analysed for left over Palladium by AAS. Figure 5 shows the $\%$ uptake of Palladium as function of treat ratio.

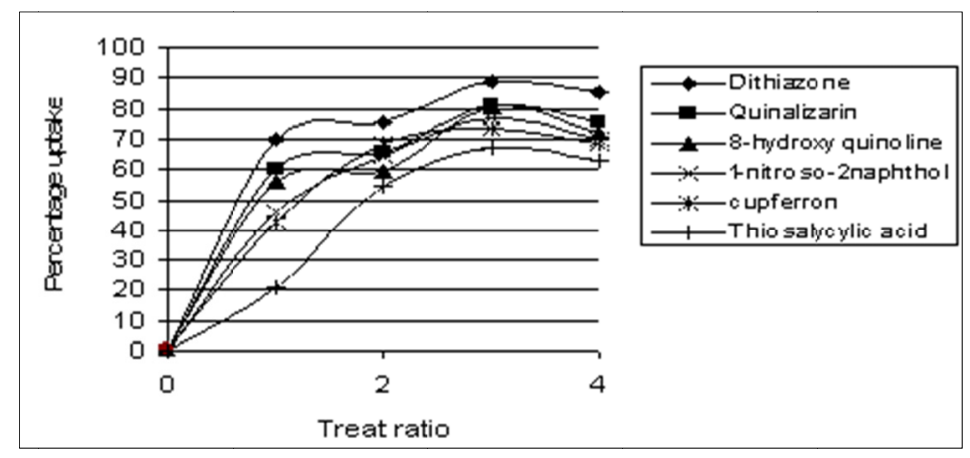

Figure 5. Uptake of Pd as function of treat ratio

\subsubsection{Effect of Agitation Speed}

After adding the emulsion to the aqueous solution from which the metal to be extracted, the permeation of the metal ion to the emulsion phase for complexation needs effective mixing of the two. Mixing beyond optimum RPM also breaks the emulsion phase which disrupts the extraction and hence the efficiency of the uptake comes down. The effect of agitation speed on \% uptake palladium in the effluent with Pallladium of strength 0.1436 $\mathrm{mM}$ of Pd was studied. Figure 6 shows the \% uptake of Palladium as a function of RPM of the impeller. 


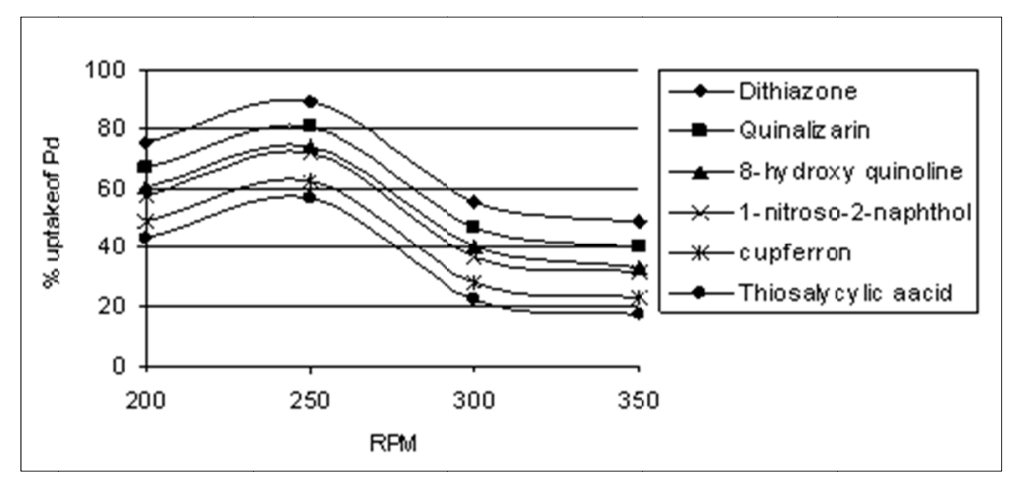

Figure 6. Optimization of RPM in the uptake of Pd

\subsubsection{Effect of Feed Concentration}

Since the uptake of the metal involves permeation and complexation of the metal ion, the extent of the uptake of the metal ion depends upon the initial strength of the feed. The \% uptake of the metal ion was studied by taking $50 \mathrm{ml}$ of the feed solution containing Palladium of strength $0.08186 \mathrm{mM}$ to $0.14367 \mathrm{mM}$ and $150 \mathrm{ml}$ of the emulsion containing the complexants of strength $0.18-0.20$ moles $/ \mathrm{L}$. The $\%$ uptake of the metal ion as a function of feed strength for various complexants is shown in Figure 7.

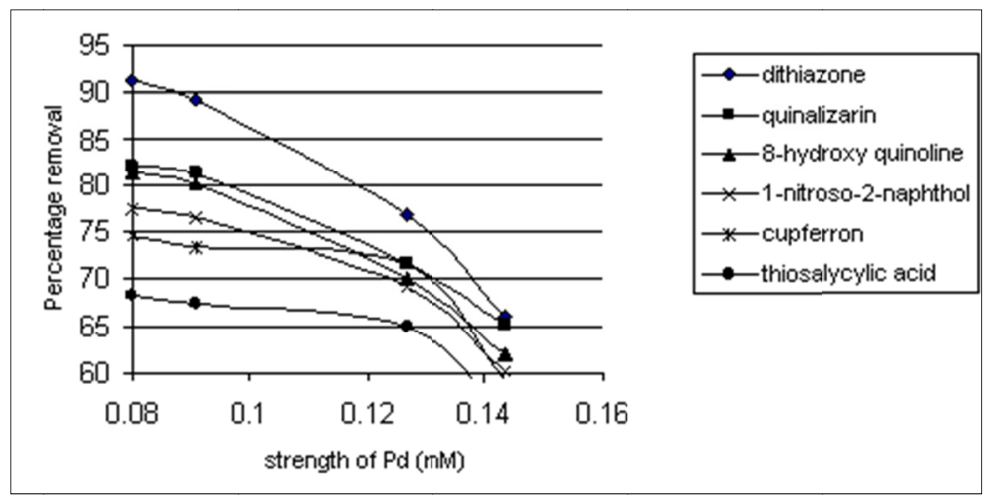

Figure 7. Uptake of Pd as function of strength of Pd

\section{Results and Discussion}

Membrane breakage and membrane swelling are the causes for the emulsion instability. This is measured by the time required for the emulsion to remain stable beyond which dispersion takes place. The various factors involved in the membrane instability are complexant concentration, surfactant concentration, mixing time and speed of agitation for the preparation of emulsion.

\subsection{Stability of Emulsion}

\subsubsection{Strength of Surfactant}

A stable emulsion needs proper surfactant in proper strength. From Figure 1a, it is observed that the emulsion stability measured in minutes is found to increase from $0.8 \%$ of the surfactant to $6 \%$ giving rise to emulsion stability duration from 10 minutes to 180 minutes and then it starts coming down to 90 minutes at $1 \% \mathrm{~V} / \mathrm{V}$. Hence the surfactant strength was fixed as $6 \% \mathrm{~V} / \mathrm{V}$ for the preparation of the emulsion.

\subsubsection{Speed of Agitator and Agitation Time}

From Figure 1b, it is observed that increasing mixing time from 5 to 20 minutes the emulsion stability was from 90 to 180 minutes and from mixing time of 20 minutes to 60 minutes the emulsion stability time was from 180 minutes to 10 minutes. Hence the mixing time for emulsion was optimized as 20 minutes.

From Figure 1c, it is observed that for mixing time of 20 minutes, the emulsion stability time was increased from 
60 to 180 minutes from 1000 RPM to 3000 RPM and then it comes down from 180 minutes to 90 minutes from RPM of 3000 to 4000 indicating the optimum agitation time of 3000 RPM for the preparation of stable emulsion.

\subsubsection{Complexant Strength}

Figure 1d indicates that membrane with high concentration of complexant decreases the stability but with low concentration of complexant decreases the solute transport rate. Hence an optimum complexant concentration was taken in order to maintain stability and solute transport. From Figure.1d it is observed that with the complexants quinalizarin, Thiosalycylic acid, 1-nitroso-2-naphthol the stability of the emulsion was found to be very high at $80 \mathrm{moles} / \mathrm{m}^{3}$ whereas with the complexants 8-hydroxyquinoline, dithiazone and cupferron the stability of the emulsion was found to be high at $70 \mathrm{moles} / \mathrm{m}^{3}$. By repeated trials, a good emulsion could be prepared which contains $6 \%(\mathrm{v} / \mathrm{V})$ surfactant, $70-80 \mathrm{moles} / \mathrm{m}^{3}$ extractant prepared at $3000 \mathrm{rpm}$ at mixing time of 20 minutes.

\subsection{Effect of Operating Parameters}

\subsubsection{Effect of $\mathrm{pH}$ of the Strippant Solution}

From Figure 2, we observe that using dithiazone when the strippant PH was between 1 to 3 , the \% uptake was 64.5-65.6 whereas from $\mathrm{pH} 3$ to 4.6, the \% uptake was 65.6-55.1. Using quinalizarin when the strippant $\mathrm{PH}$ was between 1 to 2.5 , the \% uptake was $54.8-56.9$ whereas from $\mathrm{pH} 2.5$ to 4.6 the $\%$ uptake was 56.9 to 41. Using 8-hydroxy quinoline, when the strippant $\mathrm{PH}$ was between 1 to 2.5 , the $\%$ uptake was 49.3 to 51.6 whereas from pH 2.5 to 4.6, the \% uptake was 51.6 to 36. Using 1-nitrso-2-naphthol when the strippant PH was between 1 to 1.5 , the \% uptake was 46.7 to 47.8 whereas from $\mathrm{pH} 1.5$ to 4.6 the $\%$ uptake was 47.8 to 27.8 . Using cupferron when the strippant $\mathrm{PH}$ was between 1 to 1.5 , the \% uptake was 38.9 to 44.5 whereas from $\mathrm{pH} 1.5$ to 4.6 . the $\%$ uptake was 44.5 to 23.3 . Using Thiosalycylic acid, when the strippant PH was between 1 to 1.5 , the $\%$ uptake was 19.8-20.6 whereas from $\mathrm{pH} 1.5$ to 4.6 the $\%$ uptake was 20.6-11.8.

Hence the optimum $\mathrm{pH}$ of the strippant included in the emulsion for the various complexants are as follows:

For dithiazone the $\mathrm{pH}$ of the strippant is optimized as 3, for quinalizarin and 8-hydroxy quinoline the $\mathrm{pH}$ of the strippant is optimized as is 2.5, for 1-nitroso-2-naphthol, cupferron and thiosalycylic acid the $\mathrm{pH}$ of the stripping solutuion was 1.5 .

\subsubsection{Kinetics of Removal of Palladium}

From the Figure 3 on the kinetic studies of removal of Palladium using emulsion technique, we observe that with dithiazone, \% removal ranges 34.7-65.6, with quinalizarin it ranges 22.8 to 56.9 with 8-hydroxy quinoline it ranges 21.9 to 51.6 , with 1-nitroso-2-naphthol it ranges 19.3 to 44.5 and with thiosalycylic acid it ranges 8.9 to 20.6 in a period of 15 to 60 minutes.

\subsubsection{Effect of Strength of Complexant in the Emulsion}

From Figure 4, we observe the \% removal of Pd from $0.09 \mathrm{mM}$ solution using emulsion containing different complexants of strength 0.07 to 0.2 moles / $/ \mathrm{L}$ at treat ratio of $1: 1$ at optimum $\mathrm{pH}$ of the strippant as function of moles of complexants. It is seen that the \% removal of $\mathrm{Pd}$ was maximum at $0.15 \mathrm{moles} / \mathrm{L}$ for dithiazone 8-hydroxy quionoline and 0.18 moles /L for quinalizarin, 1-nitroso-2-naphthol, cupferron and thiosalycylic acid.

\subsubsection{Effect of Treat Ratio}

The treat ratio defined as the ratio of the volume of emulsion phase to the aqueous phase containing the metal ion to be recovered plays a dominant role in the uptake of metal since more emulsion phase provides more complexant for the metal to permeate the membrane phase and hence get recovered. It is observed from Figure 5, that as the treat ratio is increased from 1:1 to $1: 3$ the \% recovery increased from 69.6 to $89.1,60.1$ to $81.4,55.7$ to $80.1,45.9$ to $76.7,42.5$ to $73.4,21.3$ to 67.4 for dithiazone, quinalizarin, 8-hydroxy quinoline, 1-nitroso-2-naphthol, cupferron, and thiosalycylic acid due to larger availiblility of the complexant. With further increase in the membrane phase, the \% recovery was not improved. Since large interfacial area between external and emulsion phase is required which gets reduced due to the formation of a dense miscelle interfacial layer at the membrane phase which resists solute transport. Hence the treat ratio for the maximum recovery of Pd was fixed at 1:3 in all the cases.

\subsubsection{Effect of Agitation Speed}

For permeation of the metal ion and subsequent reaction with the complexant present in the emulsion, sufficient agitation of the mixture is needed. If the agitation time and agitation speed is more than the optimum level there is likelihood of the breakage of the membrane and leakage of the metal ion back to the solution phase. It is 
observed from this Figure 6 that as the speed is increased from 200 to $400 \mathrm{rpm}$ the $\%$ solute recovered from the external phase changed. For dithiazone it increased from 65.4 to 69.6 at RPM 200 to 250 and then it dropped to 48.6 at 350 RPM. For Quinalizarin it increased from 55.9 to 60.1 at RPM 200 to 250 and then it dropped to 40.1 at 350 RPM. For 8-hydroxy quinoline it increased from 51.1 to 55.7 at RPM 200 to 250 and then it dropped to 33.3 at 350 RPM. For 1-nitroso-2-naphthol it increased from 42.9 to 45.9 at RPM 200 to 250 and then it dropped to 31.86 at 350 RPM. For cupferron it increased from 39.8 to 42.5 at RPM 200 to 250 and then it dropped to 22.9 at 350 RPM. For Thiosalicylic acid it increased from 19.8 to 21.3 at RPM 200 to 250 and then it dropped to 17.3 at $350 \mathrm{RPM}$, at a specified treat ratio (1:3) using complexnat at the optimum strength The agitation speed of 250 $\mathrm{rpm}$ is found to be the most effective to recover $\mathrm{Pd}^{2+}$ from external. The drop in $\%$ of metal ion recovery beyond 300 RPM is attributed due to either de emulsification induced by higher shear of impeller or due to leakage from internal stripping phase.

\subsubsection{Effect of Feed Concentration}

As seen from Figure 7, we observe that as the feed strength is increased from 0.08 to $0.1437 \mathrm{mM}$, the \% removal of Pd was found to decrease from 91.2 to 66,82 to $65.1,81.3$ to $62,77.6$ to $60.2,74.5$ to $59.3,68.2$ to 55.4 using dithiazone, quinalizarin, 8-hydroxy quinoline, 1-nitroso-2naphthol, cupferron and thiosalycylic acid respectively.

In all the cases the order of removal of Pd follows the sequence

dithiazone $>$ quinalizarin $>8$-hydroxy quinoline $>$ 1-nitroso-2-naphthol $>$ cupferron $>$ thiosalycylic acid

It is observed that increase in feed phase concentration decreases the \% solute recovered. This confirms that this technique is more effective to treat dilute streams.

\section{Conclusions}

The complexants chosen have Nitrogen, Oxygen and Sulphur for enabling complexation with Palladium. When the complexants are emulsified using span 80 as surfactant the emulsion formed could allow permeation of Palladium by providing good surface area /volume and hence the recovery of Pd was found to be effective. The order of uptake of Palladium by different complexants follow the sequence:

dithiazone $>$ quinalizarin $>8$-hydroxy quinoline $>$ 1-nitroso-2-naphthol $>$ cupferron $>$ thiosalycylic acid

\section{Acknowledgements}

The authors express their thanks to Shri Biplob Paul, Plant Superintendent, Centalised Waste Management Facility and Dr. Kumar, Superintendend (Lab), Kalpakkam Reprocessing Plant, Kalpakkam, Tamil Nadu for their unstinted support throughout the work.

\section{References}

Basualto, C., Marchese, J., Valenzuela, F., \& Acosta, A. (2003). Extraction of Molebdenum by a supported liquid membrane method. Talanta, 59(5), 999-1007.

Bloch, R., \& Finkelstein, A. (1967). Metal Ion Separation Study of Cadmium through an Emulsion Liquid Membrane Ind. Eng. Chem. Process Des. Dev., 6(3), 231-237.

Danesi, P. R., Reichley-Yinger, L., \& Rickert, P. G. (1987). Life time of supported Liquid Membranes: The influence of Interfacial Properties, chemical composition and water transport on the Long term stability of the membranes. J. Membr. Sci., 31(2/3), 117-145. http://dx.doi.org/10.1016/S0376-7388(00)82223-1

Fouad, E. A., \& Bart, H. (2008). Emulsion liquid membrane Extraction of zinc by a Hollow-fibre contactor. $J$. Membr. Sci., 307(2), 156-168. http://dx.doi.org/10.1016/j.memsci.2007.09.043

Franken, T. (1997). Liquid membranes Academic exercise or industrial partition processes. J. Membrane Technology, 85, 6-10.

Gabelman, A., \& Hwang, S. T. (1999). Hollow fibre membrane contactors. J. Membr. Sci., 159(1/2), 61-106. http://dx.doi.org/10.1016/S0376-7388(99)00040-X

Giaikwad, A. G. (2004). Synergetic transport of europium through contained supported liquid membrane using tri octyl amine and tri butyl phosphate as carriers. Talanta, 63(4), 917-926. http://dx.doi.org/10.1016/j.talanta.2003.12.041

Gu, S. X., Yu, Y. D., He, D. S. et al. (2006). Comprison of transport and separation of Cd (II) between Strip dispersion hybrid Liquid Membrane (SDHLM) and supported Liquid membrane (SLM) using tri-n-Octylamine as carrier. Sep. Sci. Technol, 51(3), 277-284.

Gu, Z. M. (2003). State of the art and the recent progress of liquid membrane separation processes. Membrane 
Sci. Technology, 214-223 (in Chinese).

Gu, Z. M., Wu, G. F., Zheng, Z. X., Li, Z. Q., Jiang, Y. L., Tang, C. J., \& Lin, P. G. (1994). Laboratory and pilot plant test of Yittrium recovery from waste water by electrostatic pseudo liquid membrane. J. Membrane Science, 93(2), 137-147. http://dx.doi.org/10.1016/0376-7388(94)80002-2

Li, Q. M., Liu, Q., Li, K., \& Tong, S. Y. (1997). Separation study of cadmium through a emulsion liquid membrane. Talanta, 44(4), 657-662. http://dx.doi.org/10.1016/S0039-9140(96)02098-X

Lin, Chen G. H. et al. (2004). Stability of Water-oil emulsion and its liquid membrane. J. Chem. Eng. Chin. Univ., $8(1), 224-230$ (in Chinese).

Neplenbroek, A. M., Bargeman, D., \& Smolders, C. A. (1992a). A supported liquid membranes: Instability effects. J. Membrane Sci., 67(2/3), 121-132. http://dx.doi.org/10.1016/0376-7388(92)80020-K

Neplenbroek, A. M., Bargeman, D., \& Smolders, C. A. (1992b). Mechanism of supported liquid membranes Degradation; Emulsion formation. J. Membr. Sci., 67(2/3), 133-148. http://dx.doi.org/10.1016/0376-7388(92)80021-B

Ren, Z. Q., Zhang, W. D., Liu, Y. M., Dai, Y., \& Cui, C. H. (2007). New liquid membrane Technology for simultaneous extraction and stripping of $\mathrm{Cu}(\mathrm{II})$ from waste water. Chem. Eng. Sci., 62(1), 6090-6101. http://dx.doi.org/10.1016/j.ces.2007.06.005

Sonawane, J. V., Pabby, A. K., \& Sastre, A. M. (2007). Au(I) extraction by LIX-79/n-heptane using the pseudo emulsion based Hollow fibre strip dispersion technique. J. Membr. Sci., 300(1/2), 147-155. http://dx.doi.org/10.1016/j.memsci.2007.05.016

Teramoto, M., Matsuyama, H., Yamashiro, T., \& Okamoto, S. (1989). Separation of Ethylene from Ethane by a Flowing liquid membrane using Silver Nitrate as a carrier. Journal of Membrane Science, 45(1/2), 115-136. http://dx.doi.org/10.1016/S0376-7388(00)80849-2

Zha, F., Fane, A. G, \& Fell, C. J. D. (1995). Effect of Surface Tension Gradients on stability of Supported liquid membranes. J. Member. Sci., 107(1/2), 75-86.

Zhang, B. C., Gozzelino, G., \& Baldi, G. (2000). State of the art on research on supported lquiquid membranes. $J$. Membrane Sci. Technol., 20(2), 46-54 (in Chinese).

\section{Copyrights}

Copyright for this article is retained by the author(s), with first publication rights granted to the journal.

This is an open-access article distributed under the terms and conditions of the Creative Commons Attribution license (http://creativecommons.org/licenses/by/3.0/). 